Title

\title{
Plasma Neutrophil Gelatinase-Associated Lipocalin (NGAL) and Creatinine Levels after Percutaneous Coronary Intervention
}

Authors:
Radias Zasra ${ }^{1}$, Syaiful Azmi², Harnavi Harun ${ }^{2}$,Yerizal Karani
1. Department of Internal Medicine, Universitas Andalas - M. Djamil General Hospital
2. Division of Nephrology, Department of Internal Medicine, Universitas Andalas - M. Djamil General Hospital
3. Division of Cardiology, Department of Internal Medicine, Universitas Andalas - M. Djamil General Hospital
Editor:
I Gde Raka Widiana

Received 9 April 2019, revised 28 July 2019, accepted 21 October 2019, published 2 December 2019

\section{Abstract}

Background. Contrast-induced nephropathy (CIN) is defined as an increase in serum creatinine $\geq 25 \%$ or $\geq 0.3 \mathrm{mg} / \mathrm{dl}$ in 48 hours after the administration of a contrast agent in the absence of other causative factors (KDIGO 2012). Neutrophil Gelatinase-Associated Lipocalin (NGAL) is a substance produced by the kidneys in acute kidney injury (AKI) caused by various insults, from ischemia to toxin-induced nephropathy. NGAL is known to increase earlier than serum creatinine levels. NGAL is also a protease-resistant polypeptide; it is released from the distal tubule, secreted to the urine or returned to the plasma (back leak), freely filtered in the glomerulus, reabsorbed in the proximal tubule through the megalin receptor endocytosis or secreted to urine. This makes NGAL detectable both in the blood and urine.

Aim. To elucidate the effect of contrast administration to serum NGAL and serum creatinine levels in patients undergoing PCI.

Methods. The study was done in the Cardiovascular Care ward in M. Djamil General Hospital, Padang, West Sumatra, Indonesia. Through consecutive 14 random sampling, 21 subjects were selected. The subjects' serum NGAL and creatinine levels were tested before PCI and 6 hours after contrast administration.

Results. The mean serum NGAL and creatinine levels of the subjects before and after contrast administration were $52.26 \mathrm{ng} / \mathrm{mL}$ vs $64.78 \mathrm{ng} / \mathrm{ml}$ and $1.1 \mathrm{mg} / \mathrm{dl} \mathrm{vs} 1.09$ $\mathrm{mg} / \mathrm{dL}$, respectively. The serum NGAL level difference before and after contrast administration was statistically significant $(p=0.003)$ whereas the serum creatinine level was not $(\mathrm{p}>0.05)$.

Conclusion. There is an increase of serum NGAL levels before and after contrast administration in patients undergoing PCI, whereas serum creatinine level was not. Future studies should be done to determine the usefulness of NGAL as an early diagnostic marker for CIN.

Corresponding author: Radias Zasra; e-mail: radiaszasra@gmail.com 


\section{Background}

Neutrophil Gelatinase Associated Lipocalin (NGAL) is a protein from the lipocalin group, a polypeptide chain consisting of 178 amino acids with a molecular weight of $25-\mathrm{kDa}$ which is bound to gelatinase from neutrophils. NGAL molecules contain $8 \beta$-strands that form a barrel shape structure with hydrophobic calyx which can bind to small lipophilic molecules. NGAL is expressed by neutrophils and various epithelial cells. In normal kidneys, NGAL is produced at very low levels; NGAL will increase if epithelial damage occurs. ${ }^{1}$ Alongside other biomarkers such as Cystatin C, Kidney Injury Molecule-1 (KIM-1), and urinary IL-18, NGAL has been profusely studied as an early diagnostic marker for acute kidney injury (AKI) caused by many conditions; cardiac surgery, sepsis, contrast administration, and kidney transplant surgery. ${ }^{2}$

In AKI, NGAL is mainly produced by the kidneys. NGAL production is caused by an array of insults to the kidney, from ischemia to renal toxicity. NGAL is also a protease-resistant polypeptide, released from the distal tubule. It is secreted to the urine or returned to the plasma (back leak), freely filtered in the glomerulus, reabsorbed in the proximal tubule through the megalin receptor endocytosis or secreted to urine. Therefore, NGAL can be detected both in the blood and urine.

Acute kidney injury (AKI) can be diagnosed with a small change in the value of serum creatinine or an acute decrease in urine production. However, when creatinine increase in diagnosis is established, kidney damage continues and some interventions will be less satisfying because the golden period of therapy has passed. For this reason, early detection of kidney damage (before a functional abnormality) is needed, to be able to initiate therapy at the beginning of the process of ongoing kidney damage. ${ }^{3}$

Based on the aforementioned background, it is important to examine the NGAL as a potential early marker of
AKI compared to creatinine as a traditional marker in patients who undergo procedures involving contrast administration.

\section{Methods}

This study is an observational study on patients who underwent PCI in M. Djamil General Hospital. The subjects were selected through consecutive sampling. The inclusion criteria were serum creatinine level $<$ $1.5 \mathrm{mg} / \mathrm{dl}$ and able to give verbal and written consent for the study. Exclusion criteria were the presence of unstable hemodynamic such as shock, presence of malignancy, and the presence of sepsis. The number of subjects needed for this study was 20.25 , which was rounded to 21. In this study, the contrast agent used was Iso-Osmolar Contrast Media (IOCM), Visipaque with a dose of $100 \mathrm{ml}$ contrast agent.

\section{Result}

In this study, the age range of the subjects was $40-71$ years with a mean age of 57.57 years. The subjects were mostly male (90.46\%). The body mass index (BMI) of the subjects in this study were categorized into normal (28.6\%), overweight $(52.4 \%)$, and obese (19\%) The diagnosis of patients undergoing PCI in this study were stable angina pectoris $(42,9 \%)$, ST-elevated myocardial infarct (STEMI) (28,6\%), non-ST elevated myocardial infarct (NSTEMI) $(9,5 \%)$, dan unstable angina pectoris (UAP) $19 \%$.

The plasma NGAL levels before PCI were $52.26 \mathrm{ng} /$ $\mathrm{mL}$, and the level 6 hours after contrast agent administration was $64.78 \mathrm{ng} / \mathrm{mL}$. The results of the Kolmogorov-Smirnov test showed data on plasma NGAL levels both before and after intervention were normally distributed. The lowest and highest levels of plasma NGAL before PCI were $32.20 \mathrm{ng} / \mathrm{ml}$ and $89.74 \mathrm{ng} / \mathrm{ml}$, whereas the lowest and highest plasma NGAL levels 
at 6 hours after administration of contrast agents were $32.32 \mathrm{ng} / \mathrm{mL}$ and $133.31 \mathrm{ng} / \mathrm{mL}$. Paired T-test results showed significantly increased plasma NGAL 6 hours after PCI from baseline $(\mathrm{p}=0.003)$.

Table 1. Baseline characteristics of subjects $(n=21)$

\begin{tabular}{lll}
\hline Subject characteristic & $\mathrm{N}(\%)$ & Mean (SD) \\
\hline $\begin{array}{l}\text { Age (years) } \\
\text { Gender }\end{array}$ & $57.57(8.95)$ \\
Male & $19(90.46 \%)$ \\
Female & $2(9.54 \%)$ & \\
Body Mass Index & \\
Normoweight & $6(28.6 \%)$ \\
Overweight & $11(52.4 \%)$ \\
Obese & $4(19 \%)$ & \\
\hline
\end{tabular}

Table 2. Serum creatinine and NGAL levels prior and 6 hours after contrast administration

\begin{tabular}{|c|c|c|c|}
\hline Variable & $\begin{array}{l}\text { Mean (SD) } \\
\text { Pre-PCl } \\
(n=21)\end{array}$ & $\begin{array}{l}6 \text { hours } \\
\text { post-contrast } \\
\text { agent adminis- } \\
\text { tration } \\
(n=21)\end{array}$ & $p$ \\
\hline $\begin{array}{l}\text { Serum } \\
\text { creatinine } \\
\text { (mg/dl) }\end{array}$ & $1.10(0.22)$ & 1.09 (0.19) & 0.57 \\
\hline $\begin{array}{l}\text { Plasma } \\
\text { NGAL } \\
\text { (ng/dl) }\end{array}$ & $\begin{array}{l}52.26 \\
(14.96)\end{array}$ & $64.78(24.50)$ & 0.003 \\
\hline
\end{tabular}

\section{Discussion}

The majority of the study's subjects were male, and the mean age of the subjects was 57.5 years old. This result is not much different from the report submitted by Shylaja et al (2017) who conducted a study of 60 patients who underwent PCI and had a higher proportion of males than female subjects ( $90 \%$ vs $10 \%)$. In the study by Shlaja et al, the average age of patients was 35.75 years. In the study conducted by Peer et al (2017) on 222 patients, the proportion of male subjects was higher than the female (men $55.8 \%$ vs women $44.2 \%$ ), and the average age of patients in this study was 48.96 years. The study by Marenzi et al (2009) also found a higher proportion of male ( $83 \%$ vs $17 \%$ ), with a mean age of 61 years in patients in their study. 3,4

In contrast-induced nephropathy (CIN), kidney damage usually ensues during 12-24 hours after contrast administration. The characteristic of AKI in CIN is non-oliguric, and the kidney injury is usually mild. However, some patients' creatinine reached $5 \mathrm{mg} / \mathrm{dl}$ and require dialysis. The patients susceptible to this condition is usually patients with pre-existing chronic kidney disease (CKD) and diabetes mellitus. The creatinine levels will then return to normal after 3-5 days. Despite the process of renal injury that occurs, the diagnosis of $\mathrm{AKI}$ in $\mathrm{CIN}$ is done after observation of increased creatinine levels in 24 hours, after the aforementioned period of injury. This will lead to a missed golden period of intervention to protect kidney function. It is important to detect kidney injury before functional abnormalities are present, so intervention can be done to improve renal outcome.

In this study, the increase of creatinine serum levels obtained 6 hours after the administration of contrast agent was not statistically significant. This is consistent with multiple studies available. The study by Kafkas et al (2016) obtained a mean serum creatinine levels before and after PCI was $0.92 \mathrm{mg} / \mathrm{dl}$ and $0.93 \mathrm{mg} / \mathrm{dl}$ in the group experiencing impaired renal function whereas in the group that did not experience impaired renal function, serum creatinine levels averaged before PCI and after PCI were $0.96 \mathrm{mg} / \mathrm{dl}$ and $0.88 \mathrm{mg} / \mathrm{dl} .{ }^{5}$ The same results were obtained by Peer et al (2016) in their study stating that the mean serum creatinine levels before PCI and 6 hours after PCI were $0.91 \mathrm{mg} / \mathrm{dl}$ and $0.98 \mathrm{mg} / \mathrm{dl}$, respectively. ${ }^{4}$ 
A relatively novel biomarker, NGAL has been studied as a potential biomarker to foretell renal injury before any functional abnormalities were observed. In healthy individuals, NGAL is usually very low and can only be detected in $67 \%$ of the population. The baseline value of this study population's NGAL level was similar to the study by Otto et al (2015), who conducted a study to see plasma NGAL levels in healthy populations, and obtain a mean plasma NGAL rate of $35 \mathrm{ng} / \mathrm{ml}$ and stated the normal NGAL plasma level is $\leq 100 \mathrm{ng} / \mathrm{ml} .{ }^{5} \mathrm{~A}$ study by Mishra et al (2003) on animals found that the renal epithelium expresses large amounts of NGAL within 30 minutes after damage due to ischemia and reperfusion, nephrotoxins, sepsis, and progressive chronic changes. ${ }^{6}$ In this study, the increase of NGAL after 6 hours of contrast administration was statistically significant. Shylaja et al (2018) conducted a study of 60 subjects undergoing PCI and observed the NGAL levels before and 6 hours after PCI also found similar results: plasma NGAL levels before PCI were $71.2 \mathrm{ng} / \mathrm{ml}$ and increased at 6 hours after PCI to $156 \mathrm{ng} / \mathrm{ml}$ in the group experiencing impaired kidney function after PCI. Similar results were also obtained by Shaker et al (2010) who conducted a study of 30 non-diabetic patients with normal creatinine levels who underwent PCI with mean NGAL levels plasma before PCI and after PCI are 52.5 $\mathrm{ng} / \mathrm{ml}$ and $88.5 \mathrm{ng} / \mathrm{ml}$, respectively. ${ }^{7,8}$ Filiopoulos et al (2014) also conducted a study to evaluate plasma NGAL levels for detection of impaired renal function after intravenous administration of contrast substances and obtain plasma NGAL levels after 6 hours of use of contrast agents can be measured to see kidney cell injury. ${ }^{1,9}$

In predicting renal functional abnormality, Nusca et al (2018) who conducted a study of 97 patients who underwent PCI found plasma NGAL levels $\geq 96 \mathrm{ng} / \mathrm{ml}$ can predict an increase in serum creatinine $>0.24 \mathrm{mg} /$ dl with a sensitivity of $53 \%$ and specificity $74 \%$. ${ }^{10}$ The same was found by Ling et al (2008) who conducted a study in China in adult patients with normal kidney function who underwent coronary angiography, getting NGAL levels increased significantly after 24 hours of angiographic procedures. ${ }^{11}$

In this study, the contrast agent used was different from the study by Peer et al (2016) which conducted a study of LOCM and IOCM contrasts with a dose average used was $115 \mathrm{ml}$ and $76 \mathrm{ml}$ and it was found that more impaired renal function occurred in the use of contrast substances with a dose of $115 \mathrm{ml}$. Briguori et al. (2006) found that kidney dysfunction occurred in about $6.5 \%$ of PCI with 122 IOCM contrast substances. ${ }^{4,12}$ Based on the hypothesis that kidney injury is dosedependent to the amount of contrast agent administered, Mehran etal(2004) performed a retrospective analysis of patients who underwent procedures with contrast agents and found that the total dose of contrast substances 30 $\mathrm{mL}$ for diagnostic measures and $<100 \mathrm{~mL}$ for intervention procedures reduce the risk of CIN. Freeman et al (2002) also found in their study that a dose of contrast agent $>5 \mathrm{~m}$ per kilogram of body weight was associated with the need for postoperative dialysis. From several other studies, the average number of LOCM contrast agents injected and considered safe ranged between 30 - $140 \mathrm{~mL}$. Further research is needed to identify safe dosages of contrast agents. ${ }^{13}$

This study has a limitation that is the level of NGAL and creatinine was not measured 48 hours after contrast administration. Therefore, whether the increase of NGAL is followed by the increase of serum creatinine level cannot be assessed.

The limitation that should be taken into account is that NGAL has already increased 6 hours after the kidney insult (a good marker for AKI) but creatinine levels just increase 48 to 72 hours after kidney insult. NGAL is immediately produced by the kidney, however, creatinine is produced by the turnover of muscular tissue, and will achieve equilibrated plasma level in a longer period. In this study, plasma creatinine levels were 
measured in 6 hours after PCI, may explain why creatinine levels have not yet increased, while NGAL levels have already increased

\section{Conclusion}

Serum NGALlevels increase 6 hours afteradministration of contrast agent for PCI, whereas serum creatinine did not. The increase of NGAL after contrast agent administration should further be studied to elucidate whether NGAL is a good marker for CIN before the onset of increased serum creatinine levels.

\section{References}

1. Singer E, Marko L, Paragus N, Barasch J, Dragun D, Muller DN, et al. Neutrophil Gelatinase-associated Lipocalin: pathophysiology and clinical applications. Acta Physiologiga. 2013 November: p. 663-72.

2. Fahling M, Seeliger E, Patzak A, Persson P. Understanding and preventing contrast-induced acute kidney injury. Nat Rev Nephrol. 2017 Mar;13(3):169-180.

3. Kafkas N, Liakos C, Zoubouloglou F, Dagadaki O, Dragasis S, Makris K. Neutrophil gelatinase-associated Lipocalin as an early marker of contrast-induced nephropathy after elective invasive cardiac procedures. Clin Cardiol. 2016 Aug;39(8):464-70.

4. Peer S, Choh NA, Gojwari TA. Incidence of contrast-induced nephropathy a prospective study. J Renal Inj Prev. 2017;6(3):192-198.

5. Otto G, Jorge H, Chung H, Knoll K, Neumann T. Plasma Neutrophil Gelatinase-Associated Lipocalin is primarily related to inflammation during sepsis: a translational approach. PLoS
ONE. 2015 April; 10(4): e0124429.

6. Haase M, Bellomo R, Devarajan P, Schlattman P, Haase-Fielitz A. The NGAL Meta-analysis Investigator Group. Accuracy of neutrophil gelatinase-associated lipocalin (NGAL) in diagnosis and prognosis in acute kidney injury: a systemic review and meta-analysis. Am J Kidney Dis. 2009; 54: p. 1012-24.

7. Shylaja TV, Sonagra A, Makandar A, Patnaik, Shanthinaidu. Serum neutrophil gelatinase-associated lipocalin as an early biomarker of acute kidney injury in subjects undergoing percutaneous transluminal coronary angiogram with normal EGFR. Int J Clin Biochem. 2018;5(1):128133

8. Shaker O, El-Shehaby A, El-khatib M. Early diagnostic markers for contrast nephropathy in patients undergoing coronary angiography. Angiology. 2010; 61: p. 731-6.

9. Filiopoulos V, Biblaki D, Vlassopoulos D. Neutrophil Gelatinase-Associated Lipocalin (NGAL): a promising biomarker of contrast-induced nephropathy after computed tomography. Ren Fail. 2014 March; 36: p. 979-86.

10. Nusca A, Marco M, Claudio P, Laura R, Massimiliano C. Early prediction contrast induced acute kidney injury by a "bedside" assessment of neutrophil gelatinase-associated lipocalin during elective percutaneous coronary intervention. 2018 May 23;13(5):e0197833.

11. Ling W, Zhaohui N, Ben H. Urinary Il-18 and NGAL as early predictive biomarkers in contrast-induced nephropathy after coronary angiography. Nephron Clin Pract. 2008; 108: p. 176-81.

12. Briguori C, Colombo A, Airoldi F, Melzi G, Carlino M, Montorfno M, et al. Gadolini- 
um-based contrast agents and nephrotoxicity in patients undergoing coronary artery procedures. Catheter Cardiovasc Interv. 2006 Feb;67(2):175-80.

13. Mehran R, Aymon E, Nikolsky E. Simple risk score for prediction of contrast-induced nephropathy after percutaneous coronary intervention: Development and initial validation. J Am Coll Cardiol. 2004; 44: p. 1393-9. 